OPEN ACCESS

Edited by:

Aldo Corsetti,

University of Teramo, Italy

Reviewed by:

Carlo Giuseppe Rizzello,

University of Bari Aldo Moro, Italy

Alex Galanis,

Democritus University of Thrace,

Greece

*Correspondence:

Rosa Aznar

rosa.aznar@uv.es

Specialty section:

This article was submitted to

Food Microbiology,

a section of the journal

Frontiers in Microbiology

Received: 03 May 2019

Accepted: 15 July 2019

Published: 31 July 2019

Citation:

Mohedano ML,

Hernández-Recio S, Yépez A,

Requena T, Martínez-Cuesta MC,

Peláez C, Russo P, LeBlanc JG,

Spano G, Aznar $R$ and López $P$

(2019) Real-Time Detection

of Riboflavin Production by

Lactobacillus plantarum Strains and Tracking of Their Gastrointestinal

Survival and Functionality in vitro

and in vivo Using mCherry Labeling.

Front. Microbiol. 10:1748.

doi: 10.3389/fmicb.2019.01748

\section{Real-Time Detection of Riboflavin Production by Lactobacillus plantarum Strains and Tracking of Their Gastrointestinal Survival and Functionality in vitro and in vivo Using mCherry Labeling}

\author{
Mari Luz Mohedano', Sara Hernández-Recio', Alba Yépez², Teresa Requena ${ }^{3}$, \\ M. Carmen Martínez-Cuesta ${ }^{3}$, Carmen Peláez ${ }^{3}$, Pasquale Russo ${ }^{4}$, Jean Guy LeBlanc ${ }^{5}$, \\ Giuseppe Spano4, Rosa Aznar ${ }^{2,6 *}$ and Paloma López ${ }^{1}$

\begin{abstract}
1 Department of Microorganisms and Plant Biotechnology, Biological Research Center (CIB-CSIC), Madrid, Spain, Food and Environment, University of Foggia, Foggia, Italy, ${ }^{5}$ Reference Centre for Lactobacilli (CERELA-CONICET), San Miguel de Tucumán, Argentina, ${ }^{6}$ Department of Preservation and Food Safety Technologies, Institute of Agrochemistry and Food Technology (IATA-CSIC), Paterna, Spain
\end{abstract} \\ ${ }^{2}$ Department of Microbiology and Ecology, University of Valencia, Valencia, Spain, ${ }^{3}$ Department of Biotechnology and Food \\ Microbiology, Institute of Food Science Research (CIAL-CSIC), Madrid, Spain, ${ }^{4}$ Department of the Science of Agriculture,
}

Some strains of lactic acid bacteria ( $\angle A B)$ produce riboflavin, a water-soluble vitamin of the B complex, essential for human beings. Here, we have evaluated riboflavin (B2 vitamin) production by five Lactobacillus plantarum strains isolated from chicha, a traditional maize-based fermented alcoholic beverage from north-western Argentina and their isogenic riboflavin-overproducing derivatives previously selected using roseoflavin. A direct fluorescence spectroscopic detection method to quantify riboflavin production in bacterial culture supernatants has been tested. Comparison of the efficiency for riboflavin fluorescence quantification with and without prior HPLC fractionation showed that the developed method is a rapid and easy test for selection of B2 vitamin-producing strains. In addition, it can be used for quantitative detection of the vitamin production in real time during bacterial growth. On the basis of this and previous analyses, the L. plantarum M5MA1-B2 riboflavin overproducer was selected for in vitro and in vivo studies after being fluorescently labeled by transfer of the pRCR12 plasmid, which encodes the mCherry protein. The labeling did not affect negatively the growth, the riboflavin production nor the adhesion of the strain to Caco-2 cells. Thus, L. plantarum M5MA1-B2[pRCR12] was evaluated for its survival under digestive tract stresses in the presence of microbiota in the dynamic multistage BFBL gut model and in a murine model. After exposure to both models, M5MA1-B2[pRCR12] could be recovered and detected by the pink color of the colonies. The results indicated a satisfactory resistance of the strain to gastric and intestinal stress conditions but a low colonization capability observed both in vitro and in vivo. Overall, L. plantarum M5MA1-B2 could be proposed as a probiotic strain for the development of functional foods.

\footnotetext{
Keywords: riboflavin, probiotic, lactic acid bacteria, Lactobacillus plantarum, fluorescent labeling
} 


\section{INTRODUCTION}

Nowadays, vitamin requirement is usually adequately supplied by a balanced diet; however, the insufficient or reduced intake of some vitamins is an important cause of nutritional deficiencies which affects susceptible groups of the population (LeBlanc et al., 2011; Mensink et al., 2013). Vitamin B2 (riboflavin) is a water-soluble vitamin which is a central and crucial component of cellular metabolism, since it is the precursor of the coenzymes flavin mononucleotide (FMN) and flavin adenine dinucleotide (FAD) (LeBlanc et al., 2011). According to the European Food Information Council, the riboflavin "Recommended Daily Amount" (EU RDA) is $1.6 \mathrm{mg}$ per day (EFSA NDA Panel, 2017) and this has to be ingested regularly, because human beings are unable to store this vitamin. Riboflavin production is a trait present in certain strains of lactic acid bacteria (LAB), which can be biotechnologically exploited to substitute the chemically synthesized vitamin in food fortification as a natural and economically viable strategy (Capozzi et al., 2012). Therefore, we screened LAB from traditionally fermented food to select strains with outstanding functional and technological traits (Carrizo et al., 2017; Jiménez et al., 2018). In addition, LAB strains which can synthesize B2 vitamin are ideal candidates to achieve vitamin overproduction by different strategies. In many Gram-positive bacteria, including some LAB strains, the synthesis of riboflavin is via the condensation of guanosine- $5^{\prime}$-triphosphate and D-ribulose- $5^{\prime}$ phosphate in seven enzymatic steps. This pathway is catalyzed by four proteins called RibA, RibG, RibB, and RibH, and their coding genes constitute the ribGBAH (rib) operon (reviewed by Thakur et al., 2015). It has been demonstrated that in Bacillus subtilis the expression of the rib operon is regulated by transcriptional attenuation at a "riboswitch" located at its $5^{\prime}$-untranslated region via FMN and riboflavin. This riboswitch contains the conserved RFN element, a region of the mRNA that can adopt two alternative secondary structures, one of which is the FMN-binding aptamer which also binds roseoflavin, a toxic riboflavin analog (Vitreschak et al., 2002; Winkler et al., 2002). It has been shown that Lactococcus lactis requires an intact rib operon for synthesis of riboflavin, and that transcription of the operon does not take place when riboflavin is present in the growth medium (Burgess et al., 2004). Moreover, these authors, as well as Sybesma et al. (2004) described the isolation of riboflavin-overproducing spontaneous mutants after exposure of L. lactis NZ9000 to roseoflavin, because by constitutive high intracellular production of riboflavin, the cells can overcome the challenge of this toxic compound (Kukanova et al., 1982). The overproducing phenotype was frequently associated with mutations in the conserved RFN regulatory region (Burgess et al., 2004). During the last decade resistance to roseoflavin has been a widely employed method to obtain B2 vitamin-overproducing LAB strains (Capozzi et al., 2011; Juarez del Valle et al., 2014). Importantly, these riboflavin-resistant strains are spontaneous, non-genetically modified organisms, and consequently should be acceptable for the production of vitamin B2-enriched foods (Burgess et al., 2006). In this context, five Lactobacillus plantarum strains isolated from Argentinian "chicha" (a fermented drink) (Elizaquível et al., 2015; Jiménez et al., 2018) were used to select B2-overproducing mutants carrying punctual mutations in the RFN region, upon their treatment with roseoflavin (Yépez et al., 2019). Moreover, determination of the mutants' riboflavin production by HPLC analysis and evaluation of their technological properties indicated that they were good candidates for their use to produce cereal-based fermented food enriched with riboflavin and, of these, $L$. plantarum M5MA1-B2 showed the best performance (Yépez et al., 2019). In addition, the probiotic potential of this strain, by synthesizing riboflavin in the human digestive tract, deserves further investigation, which has been performed in this work. One desirable characteristic of the probiotic strains is their ability to tolerate the gastro-intestinal tract (GIT) stresses. It is usually tested in vitro using conditions representing different gastric residence times and acidic pHs and bile salt concentrations. An approach to increase representativeness for the in vivo gut environment without relevant ethical concerns is the dynamic simulation of the upper gastrointestinal along with the colonic microbiota such as in the BFBL simulator (Barroso et al., 2015). This simulator allows an accurate control of environmental parameters and can be used as a tool for studying the resistance of probiotics to the GIT stresses and their interaction with the human microbiota. However, these cannot reliably predict response of bacteria to a multifactorial in vivo system. For this purpose, prior to human interventions, animal models are needed and these should be designed to mimic the conditions of how the probiotics will be administered including the dosage and mode of administration (de Moreno de LeBlanc et al., 2016).

For testing the performance of potential probiotic bacteria in vitro and in vivo genetic tools could be used. Accordingly, plasmid vectors for fluorescent labeling of $\mathrm{LAB}$ and Bifidobacterium has been developed (Castro-Bravo et al., 2017) and reviewed (Landete et al., 2016). Among these tools, we have developed the pRCR12 plasmid (Russo et al., 2015), which allows LAB fluorescent-labeling with mCherry, and it has been validated for its use in L. lactis, Lactobacillus acidophilus, Lactobacillus casei, Lactobacillus fermentum, L. plantarum, Lactobacillus sakei, and Pediococcus parvulus (Mohedano et al., 2015; Russo et al., 2015; Nácher-Vázquez et al., 2017a; Perez-Ramos et al., 2017, 2018). Moreover, the fluorescence labeling of L. fermentum, L. plantarum, L. sakei, and P. parvulus with pRCR12 has allowed visualization of these bacteria in the zebrafish gut (Russo et al., 2015; Nácher-Vázquez et al., 2017b; Perez-Ramos et al., 2018). Therefore, pRCR12 plasmid has been used in this work to label the L. plantarum strains of interest prior to assaying in vitro and in vivo their performance under GIT conditions.

\section{MATERIALS AND METHODS}

\section{Bacterial Strains and Growth Conditions}

The bacteria used in this work are presented in Table $\mathbf{1}$. The L. plantarum strains were routinely grown in de Man, 
TABLE 1 | Bacteria used in this work.

\begin{tabular}{|c|c|c|c|c|c|}
\hline Bacteria & CECT no. & Plasmid & $\begin{array}{l}\text { Antibiotic } \\
\text { resistance }\end{array}$ & Characteristics & References \\
\hline L. plantarum M5MA1 & 8962 & & & Bacterium isolated from Argentinian Chicha & Elizaquível et al., 2015 \\
\hline L. plantarum M9MM1 & 8963 & & & Bacterium isolated from Argentinian Chicha & Elizaquível et al., 2015 \\
\hline L. plantarum M9MG6 & 8965 & & & Bacterium isolated from Argentinian Chicha & Elizaquível et al., 2015 \\
\hline L. plantarum M9Y2 & 8966 & & & Bacterium isolated from Argentinian Chicha & Elizaquível et al., 2015 \\
\hline L. plantarum M9MM4 & 8964 & & & Bacterium isolated from Argentinian Chicha & Elizaquível et al., 2015 \\
\hline L. plantarum M5MA1-B2 & 9434 & & & $\begin{array}{l}\text { B2-overproducing strain selected by treatment } \\
\text { with roseoflavine }\end{array}$ & Yépez et al., 2019 \\
\hline L. plantarum M9MM1-B2 & - & & & $\begin{array}{l}\text { B2-overproducing strain selected by treatment } \\
\text { with roseoflavine }\end{array}$ & Yépez et al., 2019 \\
\hline L. plantarum M9MG6-B2 & 9435 & & & $\begin{array}{l}\text { B2-overproducing strain selected by treatment } \\
\text { with roseoflavine }\end{array}$ & Yépez et al., 2019 \\
\hline L. plantarum M9Y2-B2 & - & & & $\begin{array}{l}\text { B2-overproducing strain selected by treatment } \\
\text { with roseoflavine }\end{array}$ & Yépez et al., 2019 \\
\hline L. plantarum M9MM4-B2 & 9436 & & & $\begin{array}{l}\text { B2-overproducing strain selected by treatment } \\
\text { with roseoflavine }\end{array}$ & Yépez et al., 2019 \\
\hline L. plantarum 90[pRCR12] & - & [pRCR12] & $\mathrm{Cm}^{\mathrm{R}}$ & Source of plasmid pRCR12 & Russo et al., 2015 \\
\hline L. plantarum M5MA1[pRCR12] & - & [pRCR12] & $\mathrm{Cm}^{\mathrm{R}}$ & Strain fluorescently labeled with mCherry & This study \\
\hline L. plantarum M5MA1-B2[pRCR12] & 9402 & [pRCR12] & $\mathrm{Cm}^{\mathrm{R}}$ & Strain fluorescently labeled with mCherry & This study \\
\hline
\end{tabular}

CECT, Colección Española de Cultivos Tipo.

Rogosa, Sharpe (MRS) broth (Pronadisa, Spain) at $37^{\circ} \mathrm{C}$. The corresponding strains carrying the pRCR12 plasmid were grown in MRS broth containing chloramphenicol $(\mathrm{Cm})$ at $10 \mu \mathrm{g} / \mathrm{mL}$. In addition, to evaluate the riboflavin production, these strains were grown in a chemically defined medium (CDM) (Sánchez et al., 2008) lacking riboflavin (CDM-Rib), and to test the inducibility of expression of the rib operon the CDM medium was used supplemented with either riboflavin (CDM + Rib) or FMN $(C D M+F M N)$ at $2 \mu \mathrm{g} / \mathrm{mL}$. Solid media were prepared by addition of agar (Pronadisa) to the liquid broth at a final concentration of $1.5 \%$.

\section{pRCR12 Plasmid Isolation and Transfer to $L$. plantarum Strains}

Plasmid pRCR12 carries a transcriptional fusion of the pneumococcal $\mathrm{P}_{\mathrm{x}}$ promoter and the $\operatorname{mrfp}$ gene, whose codons are optimized for expression in LAB, and which encodes a monomeric version of the red-fluorescent protein of Discosoma sp. (García-Cayuela et al., 2012). The pRCR12 plasmid was isolated from L. plantarum 90[pRCR12] using the "JetStar 2.0 Plasmid Purification kit” (Genomed, Löhne, Germany). This strain was grown in $25 \mathrm{~mL}$ of MRS supplemented with $\mathrm{Cm}$ at $10 \mu \mathrm{g} / \mathrm{mL}$ at $37^{\circ} \mathrm{C}$, until stationary phase $\left(1 \times 10^{9}\right.$ colony forming units $(\mathrm{cfu}) / \mathrm{mL})$. The bacteria were sedimented by centrifugation at $9,300 \times g$ for $10 \mathrm{~min}$ at $4^{\circ} \mathrm{C}$ and washed with $10 \mathrm{~mL}$ of phosphate buffer saline (PBS, $\mathrm{pH}$ 7.4). Then, plasmid isolation was performed as described in the kit protocol, eluting the plasmid DNA in $160 \mu \mathrm{l}$ at approximately $100 \mu \mathrm{g} / \mathrm{mL}$. For transfer of pRCR12 to L. plantarum strains, $0.5 \mu \mathrm{g}$ of the plasmid were used for electroporation $(25 \mu \mathrm{F}, 1.3 \mathrm{kV}$, and $200 \Omega$ in $0.1 \mathrm{~cm}$ cuvettes) as previously described (Berthier et al., 1996) and transformants were selected in MRS-agar plates supplemented with $\mathrm{Cm}$ at $10 \mu \mathrm{g} / \mathrm{mL}$.

\section{Analysis of the RFN Element}

Chromosomal DNA from L. plantarum wild-type strains and their derivatives were obtained with the Microbial DNA extraction kit (Cabru, Milan, Italy) according to the manufacturer's instructions. Quantity and quality of genomic DNA were assessed using a BioTek Eon spectrophotometer (BioTek, Winooski, VT, United States) and by visualization on $0.8 \%$ agarose gel. The primers RFNFpl (CAGCGCCTTGTTTGAT) and RFNR (TGGCCGTCTTTGACTA) (Macrogen, Madrid, Spain) were used to amplify a 649-bp fragment including the rib regulatory region. The PCR were carried out in a $25-\mu \mathrm{L}$ volume reaction containing $20 \mathrm{ng}$ of genomic DNA, $5 \mu \mathrm{L}$ of $5 \times$ HotStar HiFidelity PCR Buffer, $0.2 \mathrm{~nm}$ of each primer, and $2.5 \mathrm{U} / \mu \mathrm{L}$ of the HotStar HiFidelity DNA Polymerase (Qiagen, Hilden, Germany). The thermal profile of the PCR was as follows: $95^{\circ} \mathrm{C}$ for $5 \mathrm{~min}, 35$ cycles of $95^{\circ} \mathrm{C}$ for $30 \mathrm{~s}, 53^{\circ} \mathrm{C}$ for $45 \mathrm{~s}, 72^{\circ} \mathrm{C}$ for $75 \mathrm{~s}$, and a final extension at $72^{\circ} \mathrm{C}$ for $7 \mathrm{~min}$. Clean-up was performed by using a QIAquick PCR purification kit (Qiagen), and quantification and purity of the amplicons were determined spectrophotometrically and by visualization on $1.2 \%$ agarose gel. Sequencing was performed according to the EZ-seq service (Macrogen). Multiple sequence alignments of the RFN were performed using the Clustal Omega program ${ }^{1}$.

\section{Detection and Quantification of Bacterial Culture Fluorescences} Simultaneous Measurement of Cell Growth and Fluorescence

Sterile 96-Well Optical White w/Lid Cell Culture (Thermo Fisher Scientific, Rochester, NY, United States) were used to monitor

\footnotetext{
${ }^{1}$ http://www.ebi.ac.uk/Tools/msa/clustalo
} 
simultaneously and in real time the growth and the fluorescence of L. plantarum cultures with a Varioskan Flask System (Thermo Fisher Scientific, Waltham, MA, United States).

Growth and the mCherry red fluorescence were spectrofotometrically determined as follows: overnight cultures grown in MRS were diluted in fresh medium to give an optical density at a wavelength of $600 \mathrm{~nm}\left(\mathrm{OD}_{600}\right)$ of 0.1 and $200 \mu \mathrm{L}$ of each culture were analyzed in triplicate during growth in real time in the microtiter plate. The $\mathrm{OD}_{600}$ of the cultures was measured as well as the emission of the mCherry fluorescence at a wavelength of $610 \mathrm{~nm}$ upon excitation at a wavelength of $587 \mathrm{~nm}$.

Growth and riboflavin fluorescence were spectrofotometrically determined as follows: overnight cultures grown in MRS medium were sedimented by centrifugation at $9,300 \times g, 10 \mathrm{~min}$ at room temperature, and resuspended in either CDM-Rif, CDM + Rib or CDM + FMN media to an initial $\mathrm{OD}$ at a wavelength of $480 \mathrm{~nm}\left(\mathrm{OD}_{480}\right)$ of 0.1 and three $200 \mu \mathrm{L}$ aliquots of each culture were analyzed as indicated above. The cell growth was monitored by measuring the $\mathrm{OD}_{480}$ and the riboflavin fluorescence upon excitation at a wavelength of $440 \mathrm{~nm}$ and detection of emission at a wavelength of $520 \mathrm{~nm}$.

In both cases, the experiments were performed in triplicate by incubating in the Varioskan equipment at $37^{\circ} \mathrm{C}$ and measuring $\mathrm{OD}$ and fluorescence at $30 \mathrm{~min}$ intervals.

\section{Quantification of Riboflavin Levels by Fluorescence in Culture Supernatants}

To carry out the riboflavin quantification, a calibration curve was made to correlate the fluorescence emitted by riboflavin solutions at $520 \mathrm{~nm}$ with the concentration of the compound dissolved therein (Supplementary Figure S1). To this end, serial dilutions of a solution of riboflavin in CDM at $10 \mathrm{mg} / \mathrm{mL}$ were performed, and aliquots of $0.2 \mathrm{~mL}$ of each dilution were analyzed in a 96well plate polypropylene non-sterile w/o lid Black (Nalge Nunc, Rochester, NY, United States), with an excitation wavelength of $440 \mathrm{~nm}$ and an emission wavelength of $520 \mathrm{~nm}$.

Quantification of riboflavin produced by the LAB strains was performed by measuring the fluorescence in the supernatants of cultures grown in CDM medium. To this end, CDM medium was inoculated at $\mathrm{OD}_{480}$ of 0.1 with cells recovered from MRS overnight cultures and resuspended in fresh medium. After $24 \mathrm{~h}$ incubation at $37^{\circ} \mathrm{C}, \mathrm{OD}_{480}$ was measured., bacteria were sedimented by centrifugation and $0.2 \mathrm{~mL}$ aliquots of culture supernatants were used to measure fluorescence as described above. These determinations were made in duplicate. Riboflavin concentration was estimated by interpolation of fluorescence values in the calibration curve.

\section{Determination of Riboflavin Concentration After HPLC Fractionation}

Lactobacillus plantarum strains were grown overnight in MRS at $37^{\circ} \mathrm{C}$. Then, cells were sedimented by centrifugation at $9,300 \times g$, $10 \mathrm{~min}$, at room temperature and resuspended in CDM to achieve an $\mathrm{OD}_{480}$ of 0.1 , which corresponded to $2.1 \times 10^{7} \pm 0.4 \mathrm{cfu} / \mathrm{mL}$. After incubation at $37^{\circ} \mathrm{C}$ for $24 \mathrm{~h}$, bacteria were removed by centrifugation as above and the supernatants were recovered and subjected to HPLC fractionation and fluorescence identification and quantification of riboflavin according to the previously described procedure (Jakobsen, 2008). Briefly, chromatographic analyses were performed by using a HPLC equipped with a degasser system with nitrogen, a binary pump, and a fluorescence detector (Agilent-1100 Series, Palo Alto, CA, United States), and a Zorbax Eclipse Plus C 18 [4.6 × $150 \mathrm{~mm}, 5 \mu \mathrm{m}$ internal diameter (i.d.)] analytical column with a pre-column Zorbax ODS (4.6 $\times 12.5 \mathrm{~mm}, 5 \mu \mathrm{m}$ i.d.) (Agilent Technologies). Signals were recorded by a ChemStation computer software (Agilent, Palo Alto, CA, United States). HPLC analyses were carried out by an isocratic elution at $1 \mathrm{~mL} / \mathrm{min}$, using as mobile phase a methanol/water (35:65 v/v) mixture. The eluate was monitored by a fluorescence detector set at an excitation wavelength of $440 \mathrm{~nm}$ and an emission wavelength of $520 \mathrm{~nm}$. Spectral analyses of standard were performed in order to determine LOD and LOQ. The limits of detection and quantification of riboflavin were 0.03 and $0.15 \mathrm{mg} / \mathrm{L}$, respectively.

\section{Fluorescence Microscopy}

Exponential cultures of the L. plantarum strains were sedimented and resuspended in PBS pH 7.2 to obtain a fivefold concentrated suspension. Then, without fixing, the suspensions $(10 \mu \mathrm{L})$ were used for phase contrast and fluorescent microscopy analysis with a Leica DM1000 model microscope (Leica Microsystems, Mannheim, Germany) with a light source EL6000 and the filter system TX2 ET for detection of mCherry fluorescence, respectively. The microscope was connected to a DFC3000G camera (Leica Microsystems) with a CCD sensor. The image analysis was performed using Leica Application Suite X Software (Leica Microsystems).

\section{Adhesion of $L$. plantarum Strains to Caco-2 Cells}

The Caco-2 human enterocyte cell line, obtained from the cell bank at CIB, was seeded in 24-well tissue culture plates (Falcon Microtest ${ }^{\mathrm{TM}}$, Becton Dickinson, Franklin Lakes, NJ, United States) at a final concentration of $1 \times 10^{5}$ cell/ $\mathrm{mL}$ and grown as mono-layers of differentiated cells for 14 days as previously described (Nácher-Vázquez et al., 2017a). Cell concentrations were determined as previously described (Garai-Ibabe et al., 2010).

To test the adhesion, overnight cultures of the L. plantarum strains grown in MRS were diluted to give an $\mathrm{OD}_{600}$ of 0.1 at $37^{\circ} \mathrm{C}$ and incubated until the end of the exponential phase. Then, bacteria were sedimented as indicated above, resuspended in Dulbecco's Modified Eagle Medium (DMEM, Invitrogen) and added to Caco- 2 cells at a concentration of $5 \times 10^{9} \mathrm{cfu} / \mathrm{mL}$. After incubation for $4 \mathrm{~h}$ at $37^{\circ} \mathrm{C}$ in an atmosphere containing $5 \% \mathrm{CO}_{2}$, unattached bacteria were removed by three washings with $0.5 \mathrm{~mL}$ of PBS pH 7.2. Then, Caco- 2 cells were detached from the well by incubating with $0.1 \mathrm{~mL}$ of $0.05 \%(\mathrm{w} / \mathrm{v})$ trypsin-EDTA for $7 \mathrm{~min}$ at $37^{\circ} \mathrm{C}$. The reaction was stopped by addition of $0.5 \mathrm{~mL}$ of $\mathrm{PBS} \mathrm{pH} 7.2$. The number of cellassociated bacteria was determined in two ways: (i) by plating for all strains and (ii) by measuring the mCherry fluorescence in the case of strains carrying the pRCR12 plasmid. In the 
second case, calibration curves correlating $\mathrm{cfu} / \mathrm{mL}$ (determined by plating) and fluorescence (Supplementary Figure S2) were used to establish the adhesion levels. Three independent adhesion assays were performed for each strain and each sample was tested in duplicate.

\section{Dynamic Simulation of the GIT Conditions and Feeding With L. plantarum M5MA1-B2[pRCR12]}

The BFBL gut model is a four-stage reactors system intended to simulate in vitro the small intestine (SI) and the microbial conditions of three regions (R1, R2, R3) of the human colon. At the beginning of the experiment, the colon reactors were all simultaneously inoculated with the same fecal sample from a healthy human volunteer. The colonic microbiota was allowed to stabilize, reaching the steady state after 2 weeks (stabilization period). The inoculum preparation and the nutritive medium composition were essentially as described by Barroso et al. (2015). After stabilization of the colonic microbiota, L. plantarum M5MA1-B2[pRCR12] was daily administered to the BFBL model (test period) during five consecutive days (in average $9.8 \mathrm{log}$ cfu/day). Late exponential bacterial cultures were sedimented as above and resuspended in nutrient medium adjusted to $\mathrm{pH} 2$ and added to the SI vessel. Simultaneously, the SI vessel received additional nutrient medium ( $\mathrm{pH} 2)$ and the pancreatic juice containing a mix of bile salts, $\mathrm{NaHCO}_{3}$ and pancreatin from porcine pancreas, as described previously (Barroso et al., 2015), that neutralized the acidic $\mathrm{pH}$. After $2 \mathrm{~h}$ of incubation at $37^{\circ} \mathrm{C}$, the whole content of the vessel was automatically transferred to the first colon compartment (R1) at a flow rate of $5 \mathrm{~mL} / \mathrm{min}$. The transit of colonic content between the R1, R2, and R3 compartments was controlled with level sensors that maintain their volumes at 250,400 , and $300 \mathrm{~mL}$, respectively. The whole experiment was repeated twice using fecal samples from two different volunteers.

All the vessels were maintained under anaerobic conditions by flushing $\mathrm{N}_{2}$ during the feeding and incubation in the SI vessel and during the transit of the gut content between the colon reactors. Samples were collected at regular time points $(7,9,11$, and 14 days of the stabilization period and every day during the test period) from the vessels and stored at $-20^{\circ} \mathrm{C}$ until further analysis. Also, a 3-days washout sample (a period without the addition of $L$. plantarum M5MA1-B2[pRCR12]) was analyzed. Microbiological plate count analyses were performed at the time of sampling.

\section{Microbiological Analyses}

Viable L. plantarum M5MA1-B2[pRCR12]) counts were determined by plating onto agar MRS at $37^{\circ} \mathrm{C}$ for $48 \mathrm{~h}$. Total bacteria and Lactobacillus numbers were quantified by qPCR using SYBR green methodology in a ViiA7 System (Life Technologies) using primers $968 \mathrm{~F}$ and UNI 1401 R (Nübel et al., 1996) and LabF362 and Lab-667-R (Rinttilä et al., 2004), respectively. Primers RibG-F (5'AGGTCGGTGCGGTATTAGTCAAAG-3') and RibG-R (5'-ACGCGCCTGTTCTGGTGTG-3') were designed from the
L. plantarum M5MA1-B2 genome sequence (Genbank accession number CAADEV010000001-CAADEV010000118) using the PrimerSelect tool of DNASTAR (Lasergen 14), and were used to quantify copies of the ribG gen in the L. plantarum rib operon for riboflavin biosynthesis (Capozzi et al., 2011).

\section{Analysis of SCFA and Ammonium}

Samples from the R1, R2, and R3 compartments were centrifuged $(10,000 \times g, 10 \mathrm{~min})$ and the supernatants analyzed by HPLC as described earlier (Barroso et al., 2015). Briefly, samples $(20 \mu \mathrm{L})$ were injected on a HPLC system (Jasco, Tokyo, Japan) equipped with a UV-975 detector. SCFA were separated using a Rezex ROA Organic Acids column (Phenomenex, Macclesfield, United Kingdom) using $5 \mathrm{mM}$ sulphuric acid as mobile phase. The elution profile was monitored at $210 \mathrm{~nm}$ and the identification of the peaks was carried out by comparing the retention times of target peaks with those of the standards: acetic, propionic, butyric, formic, succinic, and lactic acids. Calibration curves of these acids were carried out in the concentration range from 1 to $100 \mathrm{mM}$. Ammonium was determined using the Nessler's reagent (Sigma) as previously described (Doo et al., 2017).

\section{L. plantarum M5MA1-B2[pRCR12] Survival in an in vivo Murine Model}

Lactobacillus plantarum M5MA1-B2[pRCR12] was activated twice in MRS containing $\mathrm{Cm}$ at $10 \mu \mathrm{g} / \mathrm{mL}$. After the second activation, the strain was washed twice with sterile saline solution $(0.85 \% \mathrm{w} / \mathrm{v} \mathrm{NaCl})$ to remove any traces of the antibiotic and resuspended to its original volume in the same solution. Conventional adult BALB/c mice (male, 5 weeks old, weighing $25 \pm 3 \mathrm{~g}$ ) were obtained from the inbred animal facilities at the Centro de Referencia para Lactobacilos (CERELA-CONICET, San Miguel de Tucumán, Argentina). The animal protocol was pre-approved by the Animal Protection Committee of CERELA (protocol no. CRL-BIOT-LT-20142/A), and all experiments complied with the current laws of Argentina for the use of experimental animals. Each animal (21 in total) received a single intragastric (IG) gavage of $100 \mu \mathrm{l}$ of the bacterial suspension (corresponding to $1 \times 10^{6} \mathrm{cfu} / \mathrm{animal}$ ) or the same amount of saline solution for the control group (consisting of seven animals). After administration, three animals that received bacterial suspensions and one animal from the control group were sacrificed at $0.5,2,4,8,24$, and $36 \mathrm{~h}$ post-administration. Small and large intestines were aseptically removed, $2 \mathrm{~mL}$ sterile saline solution was added and tissues and their contents were homogenized. Serial dilutions in saline solution of the homogenates were plated on MRS-agar containing $\mathrm{Cm}$ and incubated at $37^{\circ} \mathrm{C}$ during $48 \mathrm{~h}$ and pink colonies were counted. Animal live weights were determined every day.

\section{Statistical Analysis}

In the Caco-2 cells adhesion assays, and in the experiments with the murine model, the data are expressed as a mean \pm standard deviation calculated from three independent experiments. The data were subjected to one-way analysis of variance (ANOVA) 
by using the SAS software. Tukey's test was applied to determine the significant differences between the variables at $p \leq 0.05$. Student's $t$-test $(p \leq 0.05)$ was applied for comparison of L. plantarum M5MA1-B2[pRCR12] viable counts and qPCR, SCFA and ammonium results between stabilization (control) and test periods in the colon reactors.

\section{RESULTS AND DISCUSSION}

\section{Comparative Detection and Quantification of Riboflavin by Direct Fluorescence Measurement With and Without Previous HPLC Fractionation}

Riboflavin can be detected quantitatively by measurement of its fluorescent emission at $520 \mathrm{~nm}$ after excitation at $440 \mathrm{~nm}$. Commonly, samples containing vitamin B2 are subjected to HPLC fractionation prior to its detection. Therefore, the riboflavin production by five $L$. plantarum strains from Andean origin and their isogenic riboflavin-overproducing strains, selected by treatment with roseoflavin, was investigated by this method. Bacteria were grown in defined CDM-Rib medium lacking riboflavin and fluorescent components that could interfere with the vitamin B2 quantification. Analysis of the culture supernatants grown in CDM-Rib (lacking B2 vitamin) revealed, as previously observed (Yépez et al., 2019), that riboflavin-overproducing strains produced and secreted B2 vitamin at high level in a range from 1.3 to $3.2 \mathrm{mg} / \mathrm{L}$ and ith a specific concentration referred to the biomass (estimated from the $\mathrm{OD}_{480}$ ) varying from 0.71 to 0.98 , this calculation showing that the M9MG6-B2 strain has the highest specific production (Table 2). In addition, vitamin B2 production by the wild-type strains was not detected by the HPLC analysis. Therefore, detection of riboflavin in supernatants of cultures grown in CDM-Rib was attempted by direct fluorescence measurement. For quantification, a standard curve was generated using vitamin B2 solutions dissolved in CDMRib (Supplementary Figure S1). The results depicted in Table 2 revealed that, in the culture supernatants of the riboflavinoverproducing derivative strains, the levels of the vitamin B2 were almost identical (for most of them) to those observed by the HPLC-fluorescence detection method, showing that in the presence of high levels of riboflavin direct quantification of this compound in culture supernatants could be performed. In addition, the more sensitive detection method by direct fluorescence measurement permitted the quantification of the levels of vitamin B2 secreted by the parental wild-type strains (Table 2). In previous studies of L. plantarum riboflavinoverproducing strains selected by exposure to roseoflavin, it was shown that they contain mutation at the RFN region (Burgess et al., 2006), Therefore, the DNA sequence of this region in the $L$. plantarum strains studied in this work was determined. All the wild-type strains showed the same sequence and punctual mutations were observed in the RFN region of the five riboflavin-overproducing strains (Supplementary Figure S3 and Table 2). Therefore, the effect of the mutations harbored by the B2-overproducing strains at the RFN element on the riboflavin secretion levels was estimated. To this end, ratios between concentrations of the specific riboflavin secreted by the overproducing and by its corresponding wild strain were calculated (Table 2). The highest 18-fold increase was observed for M9Y2-B2, carrying the mutation G114A, versus M9Y2. Furthermore, a similar fold increase of 7.5 and 6.5 was detected for M5MA1-B2 and M9MM1-B2 strains, respectively, which carry the same mutation G19A, even when their specific riboflavin production varied from 0.9 to 0.52 .

Finally, it should be stated that, in principle, the level of riboflavin secreted by the wild-type strains should be measurable by the HPLC method, since some of them were slightly higher than its lower quantification limit. Therefore, the lack

TABLE 2 | Analysis of riboflavin production of the indicated $L$. plantarum strains.

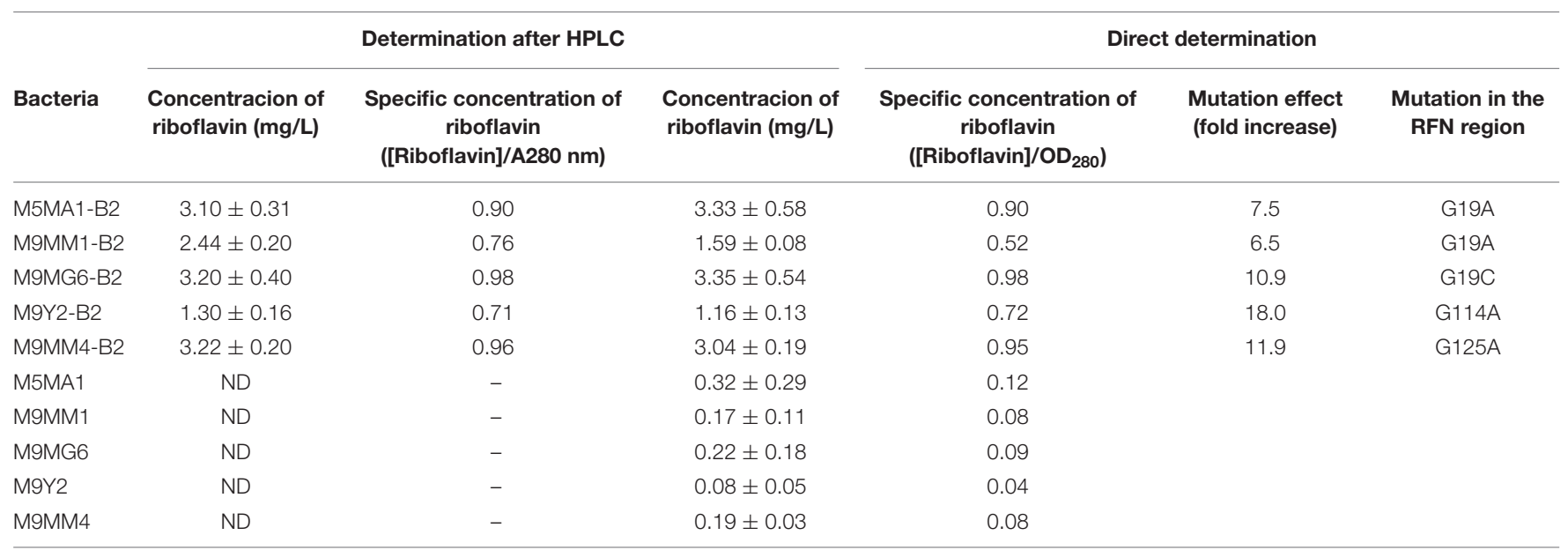

Riboflavin present in cultures supernatants was determined by measurement of its fluorescence directly or after HPLC fractionation. The OD 480 of all the cultures was $2.7 \pm 0.7$, besides those for M9Y2 and M9Y2-B2 that was $1.5 \pm 0.5$. ND, riboflavin concentration below the detection $(0.03 \mathrm{mg} / \mathrm{L})$ or quantification $(0.15 \mathrm{mg} / \mathrm{L})$ limits. The mutation effect was calculated as the ratio of the specific concentration of vitamin B2 secreted by the riboflavin-overproducing and its isogenic riboflavin-producing strain. 
of detection by this method could be due to some loss of the vitamin present in the culture supernatants during the purification steps or to the fact that without HPLC fractionation the three flavins (riboflavin and their two metabolic products FMN and FAD) could be detected together. The two hypotheses are feasible, but nevertheless our results indicate that the measurement of fluorescence could be used to study flavinproducing strains in real time.

\section{Comparative Analysis of Riboflavin Production by L. plantarum M5MA1-B2 and M5MA1 Strains}

On the basis of its high production of riboflavin $(>3 \mu \mathrm{g} / \mathrm{mL})$ and its previously detected technological properties (Jiménez et al., 2018; Yépez et al., 2019), L. plantarum M5MA1-B2, together with its isogenic parental M5MA1 strain, were selected to further investigate riboflavin production. Fluorescence emission as well as $\mathrm{OD}_{480}$ of the cultures were measured in real time during growth (Figure 1). The CDM media containing either riboflavin or FMN or lacking both flavins were tested, since the presence of these compounds seem to be involved in the regulation of the rib operon expression in other Gram-positive bacteria including L. lactis (Winkler et al., 2002; Burgess et al., 2004). The media were supplemented with either riboflavin or FMN at $2 \mu \mathrm{g} / \mathrm{mL}$, concentration at which production or consumption of the flavins during growth could be detected. Both strains grew similarly, in the three media tested, no decrease in the generation time (Gt) of the M5MA1-B2 versus M5MA1 (3.94 $\pm 0.67 \mathrm{~h}$ versus $3.7 \pm 0.55)$ was observed in CDM-Rib medium. In addition, the cultures of the riboflavin-overproducing strain showed an increase of fluorescence independently of the medium tested, indicating a constitutive synthesis of the vitamin B2. By contrast, the cultures of the parental M5MA1 strain grown in either CDM + Rib or CDM + FMN medium showed a decrease of the initial fluorescence, indicating a consumption of the flavins. Moreover, as expected for an inducible expression of the rib operon, in cultures of the M5MA1 strain grown in CDM-Rib medium, lacking flavins, an increase of fluorescence was observed. Furthermore, as expected, the final levels of fluorescence of the M5MA1 cultures were approximately threefold lower than that of the equivalent M5MA1-B2 cultures. Therefore, these results confirmed that direct measurement of fluorescence of cultures grown in CDM defined medium can be used to detect and to investigate the performance of riboflavinproducing strains.

\section{Construction and Testing of the Recombinant Fluorescently Labeled L. plantarum M5MA1[pRCR12] and M5MA1-B2[pRCR12] Strains}

Strain M5MA1-B2 had previously proved efficiency for in situ riboflavin-fortification applications in functional foods (Yépez et al., 2019). However, its potential as a probiotic strain has not been previously investigated. Therefore, with the aim of analyzing its performance under digestive tract conditions the riboflavin-overproducing strain as well as its isogenic riboflavin-producing M5MA1 strain were fluorescently labeled by transfer of the pRCR12 plasmid, which encodes the mCherry protein. The choice of this vector was based on: (i) its efficiency to confer fluorescence to the $L$. plantarum strains (Russo et al., 2015), (ii) the wavelength for maximum fluorescence emission of the mCherry $(610 \mathrm{~nm})$, which does not overlap that of the flavins $(520 \mathrm{~nm})$, and (iii) this labeling permits bacterial detection even during growth in rich medium, such as MRS (Russo et al., 2015). Thus, as expected, cultures of the recombinant M5MA1-B2[pRCR12] and M5MA1[pRCR12] strains grown in MRS but not those of their parental strains: (i) generated pink colonies (Figure 2A), (ii) contained red fluorescent bacteria detected by fluorescent microscopy (Figure 2B), and (iii) emitted red fluorescence during growth detected by fluorescent spectroscopy (Figure 2C). In addition, the use of the recombinant strains carrying the pRCR12 plasmid instead of the corresponding non-labeled strains requires that the genetic manipulation did not drastically affect the bacterial growth. Thus, the growth of the four L. plantarum strains in liquid medium was analyzed and the growth rate at the exponential phase was calculated (Figure 2C). The results revealed that growth performance of the cultures in MRS medium was not significantly affected by the fluorescent labeling, since values of $\mathrm{Gt}$ of $1.32 \mathrm{~h}$ or $1.37 \mathrm{~h}$ versus $1.07 \mathrm{~h}$ or $0.99 \mathrm{~h}$ for isogenic strains carrying or not carrying pRCR12 were detected. Furthermore, concerning to flavin production and consumption in CDM medium, M5MA1-B2[pRCR12] and M5MA1[pRCR12] behaved like M5MA1-B2 and M5MA1, respectively (Supplementary Figure S4 versus Figure 1). Consequently, labeled bacteria could be used to further assess probiotic potential of the L. plantarum strains.

\section{In vitro Adhesion of L. plantarum M5MA1 and Its Derivatives to Caco-2 Cells}

The capacity to adhere to the intestinal epithelium is one of the properties sought in probiotic bacteria. Therefore, the ability of the L. plantarum M5MA1 and its three derivative strains to adhere Caco-2 human cells was investigated following the protocol depicted in Figure 3A. When levels of bound bacteria were determined by plate counting both riboflavinoverproducing M5MA1-B2 and M5MA1-B2[pRCR12] strains showed a significant 1.5-fold higher adhesion than those of their corresponding riboflavin-producing strains M5MA1 and M5MA1[pRCR12] (Figure 3B). Moreover, the presence of the pRCR12 plasmid in both the wild-type strain and the B2 mutant resulted in a decrease of 1.4 -fold decrease of the adhesion levels (Figure 3B). Fluorescence staining of LAB (Bianchi et al., 2004) and fluorescent labeling of bifidobacteria (Castro-Bravo et al., 2017) have been used to quantify their capacity to adhere to enterocytes in vitro. Therefore, the mCherry fluorescence was used to quantify the adhesion of the L. plantarum strains carrying the pRCR12 plasmid. Standard curves of the two strains correlating cfu and fluorescence were used for quantification (Supplementary Figure S2). The levels of adhesion of both strains (Figure 3C) were slightly 


\section{L. plantarum M5MA1}
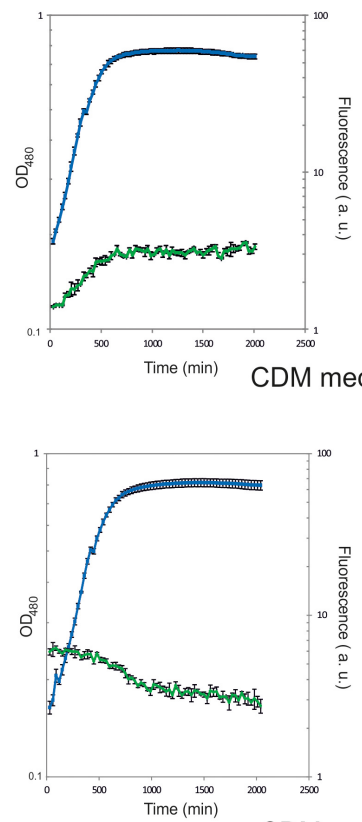

CDM medium with riboflavin

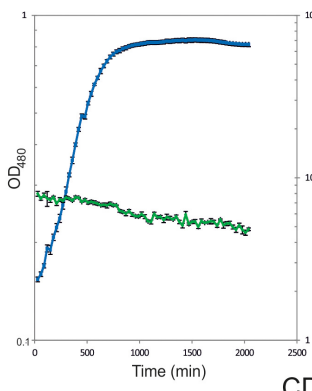

CDM medium with FMN
L. plantarum M5MA1-B2
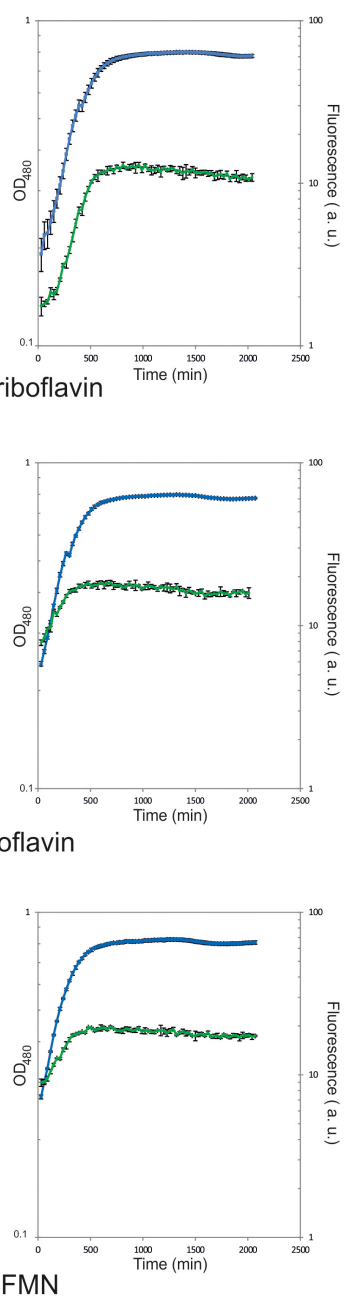

FIGURE 1 | Detection during growth of riboflavin production by L. plantarum M5MA1 and M5MA1-B2. Bacteria were grown in CDM medium without riboflavin, or supplemented with either riboflavin or FMN both at a concentration of $2 \mu \mathrm{g} / \mathrm{mL}$. The growth of cultures (blue) was monitored by measurement of OD 480 . Fluorescence emission of riboflavin (green) was recorded at $520 \mathrm{~nm}$ after excitation at a wavelength of $440 \mathrm{~nm}$.

lower than that detected by direct platting (Figure 3C) and again a higher binding level (3.1 fold) of M5MA1-B2[pRCR12] versus M5MA1[pRCR12] was observed. Thus, the overall above results revealed that the fluorescence of $L$. plantarum strains labeled with pRCR12 could be used to quantify their adhesion to Caco-2 cells. Moreover, they reveal that L. plantarum M5MA1-B2[pRCR12] can be used instead of M5MA1-B2 for testing in GIT models.

\section{Performance of $L$. plantarum M5MA1-B2[pRCR12] in the BFBL Gut Model}

The above results showed that $L$. plantarum M5MA1B2[pRCR12] could bind to Caco-2 human cells, but prior to the adhesion the bacteria have to reach the enterocytes location. Therefore, to test the capacity of the bacteria to reach and remain in the gut, the survival of this bacterium was evaluated after the passage through the simulated GIT conditions including the dynamic simulation of the human gut microbiota following the protocol depicted in Figure $\mathbf{4 A}$ and by using the BFBL gut model depicted in Figure 4B. Samples were taken during the test period and the microbial counts obtained for the SI and R1, R2, and R3 reactors are shown in Figure 4C. The fluorescent labeling of M5MA1-B2[pRCR12] permitted the straightforward determination of the strain viability by counting pink colonies detected alone when grown on MRSagar medium supplemented with $\mathrm{Cm}$, or clearly distinguishable among the rest of white colonies corresponding to members of the human microbiota, when plated on MRS-agar medium (Figure 4D). In average, after feeding 5 days the BFBL simulator with M5MA1-B2[pRCR12] at $9.8 \mathrm{log} \mathrm{cfu} /$ day (suspended in nutritional medium adjusted to $\mathrm{pH} 2$, to resemble the acidic stress of the stomach), the SI released to the colon reactors 
A

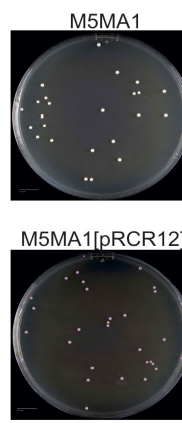

B
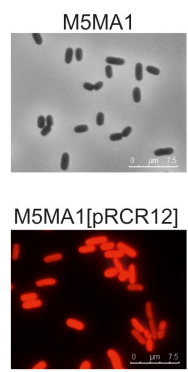
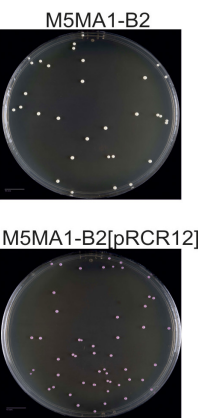

M5MA1-B2
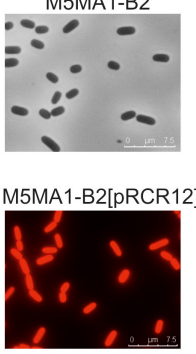

C
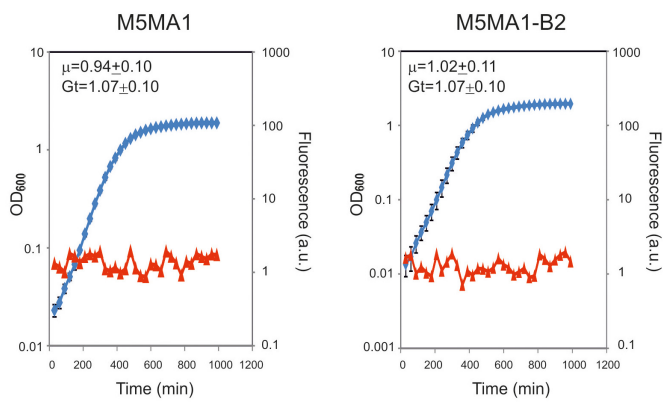

M5MA1[pRCR12]

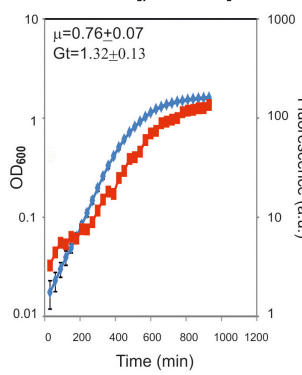

M5MA1-B2[pRCR12]

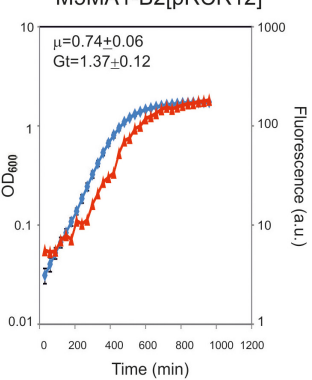

FIGURE 2 | Comparative analysis of the L. plantarum M5MA1 and M5MA1-B2 carrying or lacking pRCR12. (A) Colony phenotypes of the parental and recombinant strains. (B) Overlays of phase contrast and fluorescence images of the four $L$. plantarum strains. Visualization of bacteria by optical microscopy with an objective of $100 \times$. (C) Analysis of bacterial growth (blue) monitored by measurement of $\mathrm{OD}_{480}$ and their mCherry fluorescence emission (red) $610 \mathrm{~nm}$ upon excitation at a wavelength of $587 \mathrm{~nm}$.

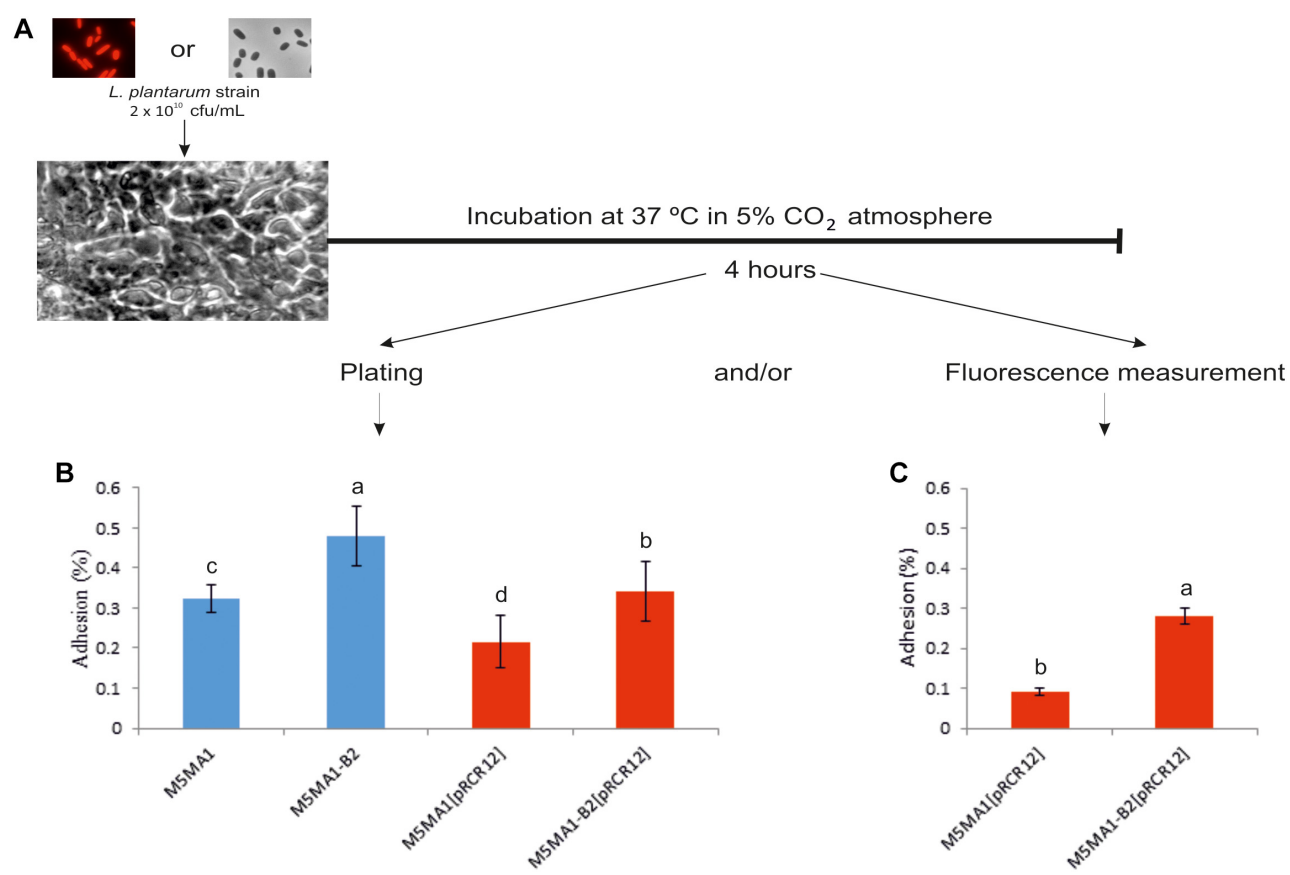

FIGURE 3 | Adhesion of $L$. plantarum M5MA1 and derivative strains to Caco-2 cells. (A) Diagram of the experimental protocol. (B) BAL adhesion levels detected by plate counting. (C) BAL adhesion levels detected by mCherry fluorescence measured at $610 \mathrm{~nm}$ upon excitation at a wavelength of $587 \mathrm{~nm}$. The standard curves depicted in Supplementary Figure $\mathbf{S} 2$ were used to correlate mCherry fluorescence and number of cfu. Statistical significances are represented by different letters that mean $P \leq 0.01$. 
A

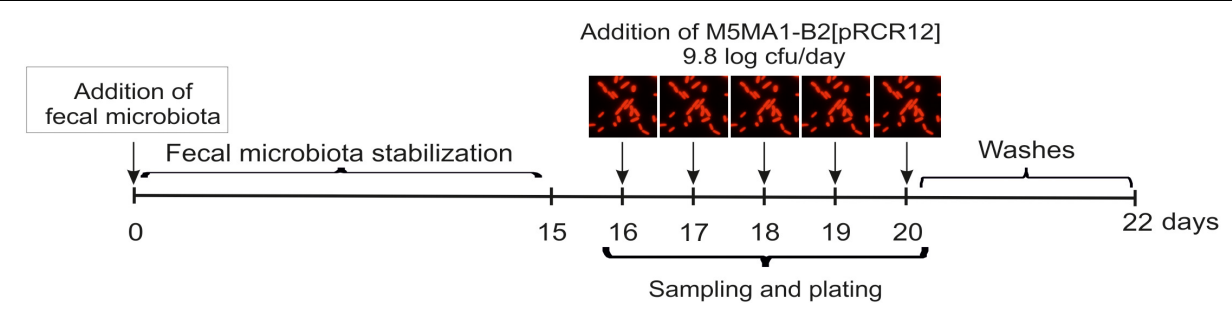

B
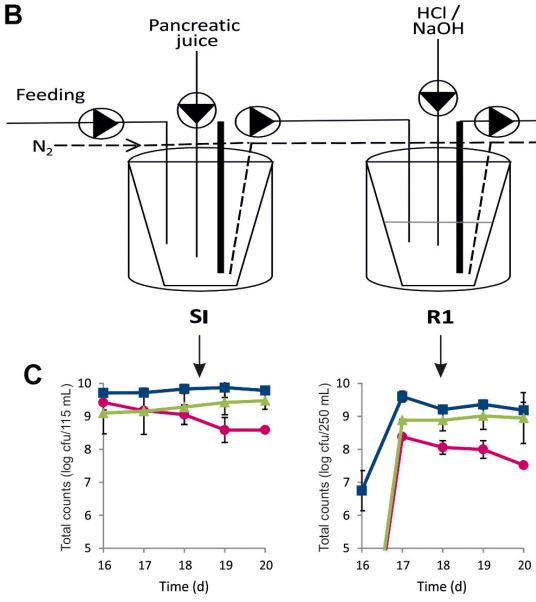

D Microbiota plus M5MA1-B2[pRCR12]

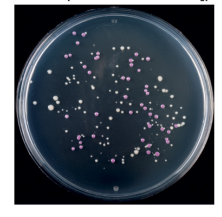

Colonies on MRS medium
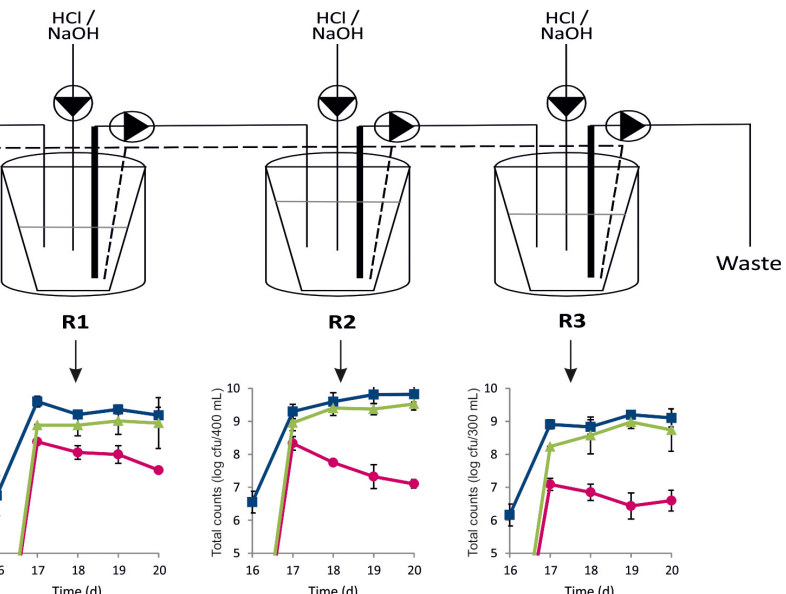

R3

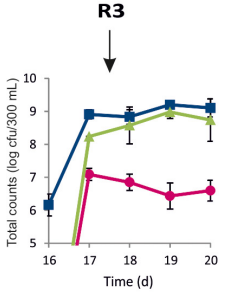

M5MA1-B2[pRCR12]

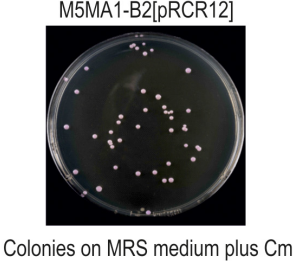

Sampling and plating

FIGURE 4 | Performance of $L$. plantarum M5MA1-B2[pRCR12] in an in vitro model of human intestinal tract. (A) Diagram of the experimental protocol. (B) Schematic representation of the BFBL gut model (SI, small intestine; R1, proximal colon; R2, transverse colon; R3, distal colon). (C) Detection of LAB in the compartments of the BFBL model by qPCR (Lactobacillus, blue; L. plantarum strains carrying ribG gene, green) and plate counting (L. plantarum M5MA1-B2[pRCR12], fucsia). (D) Detection of M5MA1-B2[pRCR12] on plates by the pink color of its colonies in presence (left plate) or absence (right plate) of microbiota.

about $8.96 \log \mathrm{cfu} /$ day during all the feeding period, indicating a satisfactory resistance of the strain to gastric and intestinal conditions. Pink colonies were observed in the plating analysis of the colon reactors content only during the feeding period with L. plantarum M5MA1-B2[pRCR12] (Figure 4C and data not shown). The pattern of detection of the L. plantarum strain by MRS-agar plating indicated a gradual reduction of viability during its colonic transit, with counts of $6.8 \mathrm{log} \mathrm{cfu} /$ day in the reactor simulating the distal colon. Moreover, the pink colonies disappeared in the three colon reactors after the 3days washout period (results not shown), indicating a low colonization capability of L. plantarum M5MA1-B2[pRCR12] in the BFBL simulator of human microbiota. Feeding the BFBL model with $L$. plantarum ribG increased accordingly the Lactobacillus and ribG counts obtained by qPCR (Figure 4C), whereas total bacteria counts showed not change between the stabilization and test periods (results not shown). No ribG gene was detected during the stabilization period, indicating low presence of riboflavin producing L. plantarum in the donors' fecal microbiota. However, some L. plantarum strains, such as the strain model WCFS1, contain an incomplete rib operon devoid of the entire ribG gene and it is unable to produce riboflavin (Kleerebezem et al., 2003). Therefore, the lack of detection of the ribG gene could be due to the presence of non-riboflavin producing L. plantarum strains. Nevertheless, this result confirms as previously proposed that the ribG presence represents a good marker for detection of riboflavin-producing bacteria (Burgess et al., 2006).

Besides monitorization of the riboflavin producing strain, products of fermentative metabolism in the colon reactors were also quantified: SCFA (acetic, propionic, butyric and formic acids) as well as lactic acid (fermentative metabolism) and ammonium (derived from proteolytic metabolism). The values detected during the stabilization and test periods are shown in the Supplementary Table S1. Lactate was determined in the three colon reactors only during all the experimentation with one volunteer fecal sample and only in the R1 vessel during the second one. In general, the feeding of the BFBL simulator with L. plantarum M5MA1-B2[pRCR12] resulted in no significant changes $(p>0.05)$ of neither SCFA nor 
ammonium contents. Therefore, this result indicates that the transient presence of the riboflavin producing strain did not affect the global metabolism of the human microbiota. In addition, the overall results showed a low colonization capability of L. plantarum M5MA1-B2[pRCR12], in spite of a good resistance to the acidic and bile salt conditions. Van den Abbeele et al. (2012) demonstrated that incorporating a mucosal environment in the SHIME dynamic gut model resulted in a more representative colonization by lactobacilli, particularly for strong mucin-adherent Lactobacillus strains. Consequently, the low colonization of L. plantarum M5MA1B2[pRCR12] in the BFBL gut model could be due to the absence of enterocytes and mucin, that will be present in an in vivo model.

\section{Survival of L. plantarum M5MA1-B2[pRCR12] in the Mouse GIT}

The above results and the fact that L. plantarum 423 strain chromosomally labeled with the mCherry coding gene was successfully investigated in a GIT mouse model (van Zyl et al., 2015) prompted us to test L. plantarum M5MA1-B2[pRCR12] in an in vivo murine model following the protocol depicted in Figure 5A. L. plantarum M5MA1-B2[pRCR12] was detected in the small intestines healthy BALB/c conventional mice until $24 \mathrm{~h}$ post-administration (Figure 5B), being the highest value $(4.0 \pm 0.3 \mathrm{cfu} / \mathrm{mL})$ detected at $30 \mathrm{~min}$ after bacterial feeding. In the large intestines smaller numbers of the bacterium were found at $30 \mathrm{~min}(1.0 \pm 0.2 \mathrm{cfu} / \mathrm{mL})$ and peaked between 2 and $8 \mathrm{~h}$ post-incubation $(3.5-3.9 \mathrm{cfu} / \mathrm{mL})$. Analysis of mouse samples by plating revealed the presence of the bacterium by the pink color of its colonies (Figure 5C). No pink colonies were found in the control mice that were administered with saline solution. From these results it can be inferred that although there was a loss of bacterial viability during the passage from the stomach to the intestines (i.g. administration of log 6.0), large numbers were recovered in the small intestines $30 \mathrm{~min}$ after administration and in the large intestines starting at $2 \mathrm{~h}$ post-administration. These results confirm the in vitro studies that showed that the strain was able to resist the conditions of the gastrointestinal tract. Since the strain was not recovered after $24 \mathrm{~h}$ post-administration, it can be concluded that although the strain can survive the passage through the gastrointestinal tract, it cannot colonize in mice. These results suggest that continuous administration of the strain (on a daily basis) would be required to exert a biological activity (produce riboflavin) at the site of interest (small intestines where the vitamin would be absorbed). Probiotic colonization is usually low, but important is the activity as transient metabolism or host
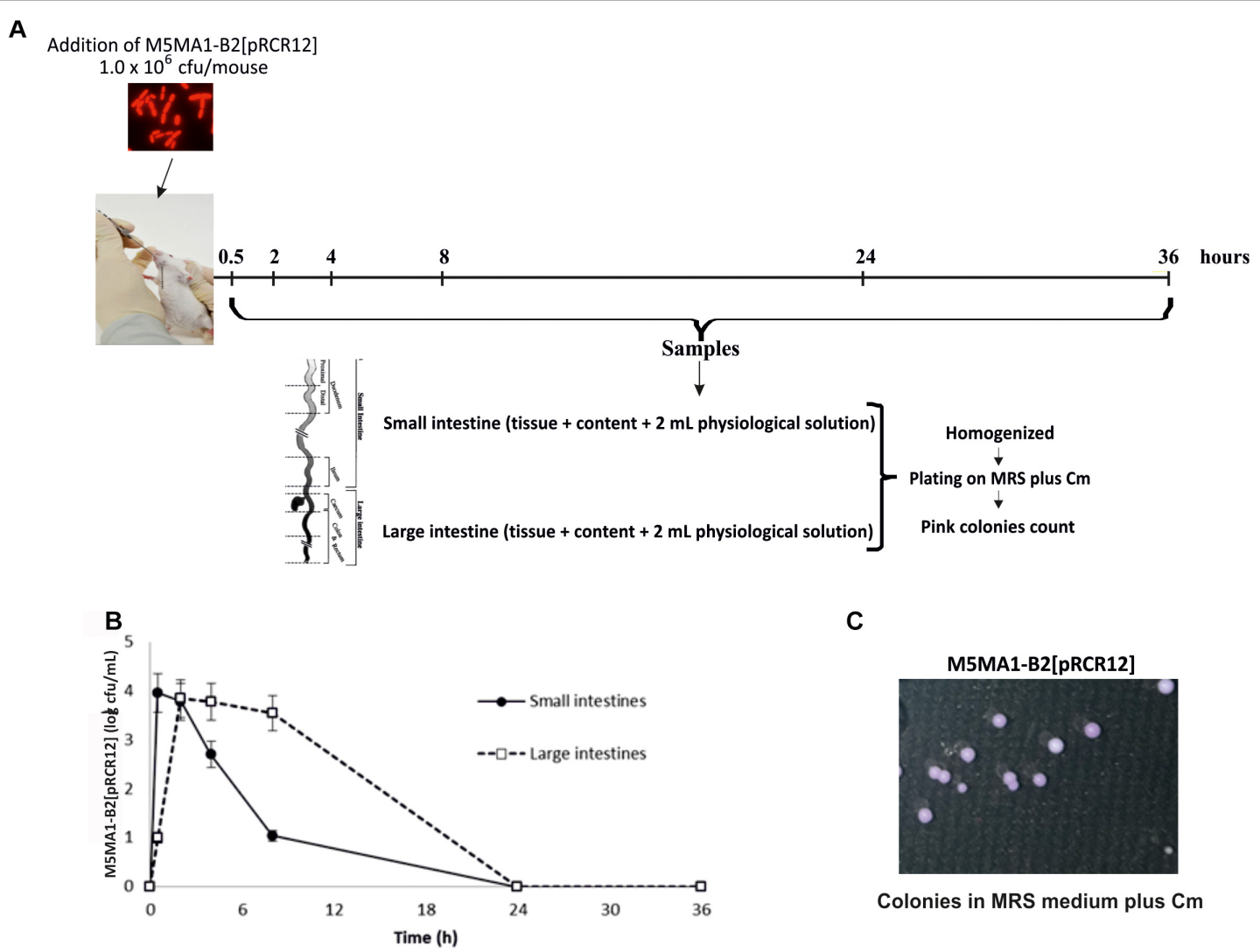

FIGURE 5 | Performance of L. plantarum M5MA1-B2[pRCR12] in mouse digestive tract. (A) Diagram of the experimental protocol. (B) M5MA1-B2[pRCR12] recovered from mice intestines by plating. (C) M5MA1-B2[pRCR12] red colonies detected after plating of a sample from small intestine taken $4 \mathrm{~h}$ after $L A B$ administration in MRS supplemented with $\mathrm{Cm}$. 
interaction. In any case, the low colonization of L. plantarum M5MA1-B2[pRCR12] in the in vivo model was in accordance with the results obtained in the in vitro BFBL gut model.

\section{CONCLUSION}

We have optimized a direct fluorescence spectroscopic quantitative detection method of vitamin B2 that could be useful for a fast selection of riboflavin overproducing LAB. Labeling with the pRCR12 plasmid expressing the red fluorescent mCherry protein has generated an attractive tool to evaluate the survival of candidate probiotic strains under digestive tract conditions in the presence of microbiota in the dynamic multistage BFBL gut model, and to quantify the adhesion level to Caco-2 human cells. Moreover, this construction has been successfully employed to track probiotic L. plantarum strains within the gut by using a murine model and bacterial platting. Therefore, the proposed approaches could be implemented, by using both in vitro and in vivo models as a workflow to select L. plantarum strains with application in the field of functional foods.

\section{DATA AVAILABILITY}

Publicly available datasets were analyzed in this study. This data can be found at: https://www.ncbi.nlm.nih.gov/nuccore/ NZ_CAADEV000000000.1.

\section{ETHICS STATEMENT}

Conventional adult BALB/c mice (male, 5 weeks old, weighing $25 \pm 3 \mathrm{~g}$ ) were obtained from the inbred animal facilities at the Centro de Referencia para Lactobacilos (CERELA-CONICET, San Miguel de Tucumán, Argentina). The animal protocol was pre-approved by the Animal Protection Committee of the CERELA (protocol no. CRL-BIOT-LT-20142/A), and all experiments complied with the current laws of Argentina for the use of experimental animals.

\section{REFERENCES}

Barroso, E., Cueva, C., Peláez, C., Martínez-Cuesta, M. C., and Requena, T. (2015). Development of human colonic microbiota in the computer-controlled dynamic simulator of the gastrointestinal tract SIMGI. LWT - Food Sci. Technol. 61, 283-289. doi: 10.1016/j.lwt.2014.12.014

Berthier, F., Zagorec, M., Champomier-Vergès, M., Ehrlich, S. D., and Morel-Deville, F. (1996). Efficient transformation of Lactobacillus sake by electroporation. Microbiology 142, 1273-1279. doi: 10.1099/13500872-142-51273

Bianchi, M. A., Del Rio, D., Pellegrini, N., Sansebastiano, G., Neviani, E., and Brighenti, F. (2004). A fluorescence-based method for the detection of adhesive properties of lactic acid bacteria to Caco-2 cells. Lett. Appl. Microbiol. 39, 301-305. doi: 10.1111/j.1472-765X.2004.01589.x

Burgess, C., O’Connell-Motherway, M., Sybesma, W., Hugenholtz, J., and van Sinderen, D. (2004). Riboflavin production in Lactococcus lactis: potential for in situ production of vitamin-enriched foods. Appl. Environ. Microbiol. 70, 5769-5777. doi: 10.1128/AEM.70.10.5769-5777.2004

\section{AUTHOR CONTRIBUTIONS}

$\mathrm{MM}$ and SH-R performed all the in vitro analysis of the LAB. AY provided the background for handling the riboflavinproducing $\mathrm{LAB}$. TR, MM-C, and $\mathrm{CP}$ contributed to the analysis of performance of $\mathrm{LAB}$ under digestive tract conditions in interaction with the human microbiome. JL performed the LAB analysis in the animal model. PR and GS were responsible for processing and the HPLC analysis of the riboflavin present in supernatants of bacterial and Caco-2 cultures, and the design of strategies to develop and analyze the bacterial recombinant strains and corrected the manuscript. GS, PL, and RA participated in the study conception, data interpretation, and generated the final version of the manuscript. All authors listed have read and approved the final version of the manuscript.

\section{FUNDING}

This work was supported by the Spanish Ministry of Economy and Competitiveness (Grants AGL2016-75951-R, RTI2018097114-B-I00, PCIN-2017-075, and PCIN-2017-003), the Ibero-American Program of Science and Technology for the Development (CYTED, Strategic Project Ref: 917PTE0537), SOURDOMICS Cost Action CA1801, and the European Cooperation in Science and Technology (COST).

\section{ACKNOWLEDGMENTS}

We thank Dr. Stephen W. Elson for critical reading of the manuscript. We thank Dr. Guillermo Padilla Alonso for his valuable assistance in the bio-statistical analysis.

\section{SUPPLEMENTARY MATERIAL}

The Supplementary Material for this article can be found online at: https://www.frontiersin.org/articles/10.3389/fmicb. 2019.01748/full\#supplementary-material

Burgess, C. M., Smid, E. J., Rutten, G., and van Sinderen, D. (2006). A general method for selection of riboflavin-overproducing food grade micro-organisms. Microb. Cell Fact. 5:24. doi: 10.1186/1475-2859-5-24

Capozzi, V., Menga, V., Digesù, A. M., De Vita, P., van Sinderen, D., Cattivelli, L., et al. (2011). Biotechnological production of vitamin B2-enriched bread and pasta. J. Agric. Food Chem. 59, 8013-8020. doi: 10.1021/jf201519h

Capozzi, V., Russo, P., Dueñas, M. T., López, P., and Spano, G. (2012). Lactic acid bacteria producing B-group vitamins: a great potential for functional cereals products. Appl. Microbiol. Biotechnol. 96, 1383-1394. doi: 10.1007/s00253-0124440-2

Carrizo, S. L., Montes de Oca, C. E., Hebert, M. E., Saavedra, L., Vignolo, G., LeBlanc, J. G., et al. (2017). Lactic acid bacteria from andean grain amaranth: a source of vitamins and functional value enzymes. J. Mol. Microbiol. Biotechnol. 27, 289-298. doi: 10.1159/000480542

Castro-Bravo, N., Hidalgo-Cantabrana, C., Rodriguez-Carvajal, M. A., RuasMadiedo, P., and Margolles, A. (2017). Gene replacement and fluorescent labeling to study the functional role of exopolysaccharides in Bifidobacterium animalis subsp. lactis. Front. Microbiol. 8:1405. doi: 10.3389/fmicb.2017.01405 
de Moreno de LeBlanc, A., del Carmen, S., Chatel, J.-M., Azevedo, V., Langella, P., Bermudez-Humaran, L., et al. (2016). Evaluation of the biosafety of recombinant lactic acid bacteria designed to prevent and treat colitis. J. Med. Microbiol. 65, 1038-1046. doi: 10.1099/jmm.0.000323

Doo, E.-H., Chassard, C., Schwab, C., and Lacroix, C. (2017). Effect of dietary nucleosides and yeast extracts on composition and metabolic activity of infant gut microbiota in PolyFermS colonic fermentation models. FEMS Microbiol. Ecol. 93:fix088. doi: 10.1093/femsec/fix088

Elizaquível, P., Pérez-Cataluña, A., Yépez, A., Aristimuño, C., Jiménez, E., Cocconcelli, P. S., et al. (2015). Pyrosequencing vs. culture-dependent approaches to analyze lactic acid bacteria associated to chicha, a traditional maize-based fermented beverage from Northwestern Argentina. Int. J. Food Microbiol. 198, 9-18. doi: 10.1016/j.ijfoodmicro.2014.12.027

EFSA NDA Panel (EFSA Panel on Dietetic Products, Nutrition and Allergies), Turck, D., Bresson, J.-L., Burlingame, B., Dean, T., Fairweather-Tait, S., Heinonen, M., et al. (2017). Scientific opinion on dietary reference values for riboflavin. EFSA J. 15:4919. doi: 10.2903/j.efsa.2017.4919

Garai-Ibabe, G., Dueñas, M. T., Irastorza, A., Sierra-Filardi, E., Werning, M. L., López, P., et al. (2010). Naturally occurring 2 -substituted (1,3)- $\beta$-Dglucan producing Lactobacillus suebicus and Pediococcus parvulus strains with potential utility in the production of functional foods. Bioresour. Technol. 101, 9254-9263. doi: 10.1016/j.biortech.2010.07.050

García-Cayuela, T., de Cadinanos, L. P., Mohedano, M. L., de Palencia, P. F., Boden, D., Wells, J., et al. (2012). Fluorescent protein vectors for promoter analysis in lactic acid bacteria and Escherichia coli. Appl. Microbiol. Biotechnol. 96, 171-181. doi: 10.1007/s00253-012-4087-z

Jakobsen, J. (2008). Optimisation of the determination of thiamin, 2(1-hydroxyethyl)thiamin, and riboflavin in food samples by use of HPLC. Food Chem. 106, 1209-1217. doi: 10.1016/j.foodchem.2007. 06.008

Jiménez, E., Yépez, A., Pérez-Cataluña, A., Ramos Vásquez, E., Zúñiga Dávila, D., Vignolo, G., et al. (2018). Exploring diversity and biotechnological potential of lactic acid bacteria from tocosh - traditional peruvian fermented potatoes - by high throughput sequencing (HTS) and culturing. LWT - Food Sci. Technol. 87, 567-574. doi: 10.1016/j.lwt.2017.09.033

Juarez del Valle, M., Laiño, J. E., Savoy, de Giori, G., and LeBlanc, J. G. (2014). Riboflavin producing lactic acid bacteria as a biotechnological strategy to obtain bio-enriched soymilk. Food Res. Int. 62, 1015-1019. doi: 10.1016/j.foodres.2014. 05.029

Kleerebezem, M., Boekhorst, J., van Kranenburg, R., Molenaar, D., Kuipers, O. P., Leer, R., et al. (2003). Complete genome sequence of Lactobacillus plantarum WCFS1. Proc. Natl. Acad. Sci. U.S.A. 100, 1990-1995.

Kukanova, A. I., Zhdanov, V. G., and Stepanov, A. I. (1982). Bacillus subtilis mutants resistant to roseoflavin. Genetika 18, 319-321.

Landete, J. M., Medina, M., and Arqués, J. L. (2016). Fluorescent reporter systems for tracking probiotic lactic acid bacteria and Bifidobacteria. World J. Microbiol. Biotechnol. 32:119. doi: 10.1007/s11274-016-2077-5

LeBlanc, J. G., Laino, J. E., del Valle, M. J., Vannini, V., van Sinderen, D., Taranto, M. P., et al. (2011). B-group vitamin production by lactic acid bacteria-current knowledge and potential applications. J. Appl. Microbiol. 111, 1297-1309. doi: 10.1111/j.1365-2672.2011.05157.x

Mensink, G. B. M., Fletcher, R., Gurinovic, M., Huybrechts, I., Lafay, L., SerraMajem, L., et al. (2013). Mapping low intake of micronutrients across Europe. Br. J. Nutr. 110, 755-773. doi: 10.1017/S000711451200565X

Mohedano, M. L., García-Cayuela, T., Perez-Ramos, A., Gaiser, R. A., Requena, T., and López, P. (2015). Construction and validation of a mCherry protein vector for promoter analysis in Lactobacillus acidophilus. J. Ind. Microbiol. Biotechnol. 42, 247-253. doi: 10.1007/s10295-014-1567-4

Nácher-Vázquez, M., Iturria, I., Zarour, K., Mohedano, M. L., Aznar, R., Pardo, M. A., et al. (2017a). Dextran production by Lactobacillus sakei MN1 coincides with reduced autoagglutination, biofilm formation and epithelial cell adhesion. Carbohydr. Polym. 168, 22-31. doi: 10.1016/j.carbpol.2017.03.024

Nácher-Vázquez, M., Ruiz-Maso, J. A., Mohedano, M. L., Del Solar, G., Aznar, R., and Lopez, P. (2017b). Dextransucrase expression is concomitant with that of replication and maintenance functions of the pMN1 Plasmid in Lactobacillus sakei MN1. Front. Microbiol. 8:2281. doi: 10.3389/fmicb.2017.02281

Nübel, U., Engelen, B., Felske, A., Snaidr, J., Wieshuber, A., Amann, R. I., et al. (1996). Sequence heterogeneities of genes encoding 16S rRNAs in Paenibacillus polymyxa detected by temperature gradient gel electrophoresis. J. Bacteriol. 178, 5636-5643. doi: 10.1128/jb.178.19.5636-5643.1996

Perez-Ramos, A., Mohedano, M. L., Pardo, M. A., and Lopez, P. (2018). Beta-glucan-producing Pediococcus parvulus 2.6: test of probiotic and immunomodulatory properties in zebrafish models. Front. Microbiol. 9:1684. doi: 10.3389/fmicb.2018.01684

Perez-Ramos, A., Werning, M. L., Prieto, A., Russo, P., Spano, G., Mohedano, M. L., et al. (2017). Characterization of the sorbitol utilization cluster of the probiotic pediococcus parvulus 2.6: genetic, functional and complementation studies in heterologous hosts. Front. Microbiol. 8:2393. doi: 10.3389/fmicb.2017. 02393

Rinttilä, T., Kassinen, A., Malinen, E., Krogius, L., and Palva, A. (2004). Development of an extensive set of $16 \mathrm{~S}$ rDNA-targeted primers for quantification of pathogenic and indigenous bacteria in faecal samples by realtime PCR. J. Appl. Microbiol. 97, 1166-1177. doi: 10.1111/j.1365-2672.2004. 02409.x

Russo, P., Iturria, I., Mohedano, M. L., Caggianiello, G., Rainieri, S., Fiocco, D., et al. (2015). Zebrafish gut colonization by mCherry-labelled lactic acid bacteria. Appl. Microbiol. Biotechnol. 99, 3479-3490. doi: 10.1007/s00253-014-6351-x

Sánchez, C., Neves, A. R., Cavalheiro, J., Moreira dos Santos, M., García-Quintáns, N., López, P., et al. (2008). The contribution of citrate metabolism to the growth of Lactococcus lactis CRL264 at low pH. Appl. Environ. Microbiol. 74, 1136-1144. doi: 10.1128/aem.01061-07

Sybesma, W., Burgess, C., Starrenburg, M., Sinderen, D. V., and Hugenholtz, J. (2004). Multivitamin production in Lactococcus lactis using metabolic engineering. Metab. Eng. 6, 109-115. doi: 10.1016/j.ymben.2003.11.002

Thakur, K., Tomar, S. K., and De, S. (2015). Lactic acid bacteria as a cell factory for riboflavin production. Microb. Biotechnol. 9, 441-451. doi: 10.1111/1751-7915. 12335

Van den Abbeele, P., Roos, S., Eeckhaut, V., MacKenzie, D. A., Derde, M., Verstraete, W., et al. (2012). Incorporating a mucosal environment in a dynamic gut model results in a more representative colonization by Lactobacilli. Microb. Biotechnol. 5, 106-115. doi: 10.1111/j.1751-7915.2011.00308.x

van Zyl, W. F., Deane, S. M., and Dicks, L. M. T. (2015). Use of the mCherry fluorescent protein to study intestinal colonization by Enterococcus mundtii ST4SA and Lactobacillus plantarum 423 in mice. Appl. Environ. Microbiol. 81, 5993-6002. doi: 10.1128/aem.01247-15

Vitreschak, A. G., Rodionov, D. A., Mironov, A. A., and Gelfand, M. S. (2002). Regulation of riboflavin biosynthesis and transport genes in bacteria by transcriptional and translational attenuation. Nucleic Acids Res. 30, 3141-3151. doi: $10.1093 /$ nar/gkf433

Winkler, W. C., Cohen-Chalamish, S., and Breaker, R. R. (2002). An mRNA structure that controls gene expression by binding FMN. Proc. Natl. Acad. Sci. U.S.A. 99, 15908-15913. doi: 10.1073/pnas.212628899

Yépez, A., Russo, P., Spano, G., Khomenko, I., Biasioli, F., Capozzi, V., et al. (2019). In situ riboflavin fortification of different kefir-like cereal-based beverages using selected Andean LAB strains. Food Microbiol. 77, 61-68. doi: 10.1016/j.fm.2018. 08.008

Conflict of Interest Statement: The authors declare that the research was conducted in the absence of any commercial or financial relationships that could be construed as a potential conflict of interest.

Copyright (C) 2019 Mohedano, Hernández-Recio, Yépez, Requena, Martínez-Cuesta, Peláez, Russo, LeBlanc, Spano, Aznar and López. This is an open-access article distributed under the terms of the Creative Commons Attribution License (CC BY). The use, distribution or reproduction in other forums is permitted, provided the original author(s) and the copyright owner(s) are credited and that the original publication in this journal is cited, in accordance with accepted academic practice. No use, distribution or reproduction is permitted which does not comply with these terms. 